UDC 316.34/.35:1/14:81

Alla MARCHYSHYNA, Anatolii SKRYPNYK

\title{
QUEER: A PHILOSOPHY PHENOMENON, A SOCIAL CONSTRUCT, A LANGUAGE SIGN
}

\begin{abstract}
The paper considers the ontology of queer as interpreted in philosophy, social studies and language. The short history of the concept analysed sheds light on transformations of its semantic structure. Queer is viewed inseparably from gender theory, where it gets apparent representation as a queer gender identity. The diffusive and trespassing nature makes queer contrary to stable and traditionally immutable sex/gender dichotomy with the normative male/female components. Queer violation of this long-established standard results in revolutionary shifts in the philosophy of human sex/gender freedom of manifestation and recognition, formation and alteration of social stereotypes, introduction and spread of verbal means serving the lingual signs of queer in general and queer gender identity, in particular. Texts of scholarly, publicist and functional literary styles depict "queer" differently depending on the objectives of each register and the appropriate scope of linguistic tools.
\end{abstract}

Keywords: gender, identity, lingual sign, queer, sex, stereotype, text.

Transformation of scholarly paradigms in the epoch of postmodernism, as well as reaction to the challenges of the globalized world, result in a revision of the stereotype principles of social interaction and relocation of the crucial figures on the chessboard of moral and value. Here belong such concepts as 'sex', 'gender', 'sexuality', the correlation and representation of which generally constitute the present-day widely acknowledged understanding of gender identity. The traditional sex dichotomy man/woman used to be actualized as male/female, the inherent properties of those latter being synchronically formed and approved by society. Until this established alliance provoked no doubts, the terms 'sex' and 'gender' alongside with the corresponding phenomena were considered synonym- ic. Hardly the scholars (S. de Beauvoir, S. Freud, E. Fromm, R. Lakoff, M. Mead, A. Oakley, G. Rubin, R. Stoller, etc.) entered upon the first studies of distinctions between these, and the inborn nature of sex and constructivist character of gender, a well-defined line of differentiation was drawn.

Since the middle of the $19^{\text {th }}$ century, the term "queer" had been operated to stand for womanlike men or homosexual practices what was both stigmatized as being a violation of physiological, moral, and social norms and signalled offensive identification. It served the sign of "accusation, pathologisation, insult" (Butler, 1993, p. 226). Besides, "queer" was employed as a narrowed umbrella term for LGBT during the socalled neo-liberal times. As M. Escudero-Alias 
(2009) states, "queer" stands for "resistance to binary oppositions, such as male/female, masculinity/femininity, heterosexuality/homosexuality" (p. 3). This concept fixed the deformation of heteronormative stereotypes what is objectivized in the denotative meaning of the lexeme under analysis: strange, odd; slightly ill; homosexual" (adj.), "(informal, offensive) a homosexual man (noun)" (see "Oxford English Dictionary"). At this primary stage, "queer" comprised both nonnormative sexualities and such other categories of identity as race and class, appealing to its positive social apprehension.

Gradually, social apprehension of "queer" and queers acquired positive interpretation. In 1990, there was a gay parade in New York where a leaflet entitled 'Queers Read This' which aimed at disproving the wide-spread pejorative connotation of the term. Moreover, "the resignification of "queer" has resulted in the multiplication of meanings linked to the notions of gender and sexuality" (Escudero-Alias, 2009, p. 14). The concept in question split the traditionally stable twain gender/sexuality into a plurality of performances and freedom of combination. The unfolding of the "queer" narrative in the social and cultural discourse as options of sex/sexuality/gender combinations is theoretically grounded by J. Butler $(1993$; 1990) in her famous statement of "gender as performance".

From its origin as a complex concept and penetration into a public sphere, "queer" was labelled a symbol of the negative societal stereotype that caused expression of homonegativity and inspired a public debate concerning both the "legalization" of the concept and new semantic structure of the lexeme itself. The whole essence of "queer" revolted against heterosexism as the only normative sex/gender combination which queer-activists considered nothing more but a "gendered expression of biology", or "biologic expression of gender" (Emslie \& Hunt, 2008, p. $809)$. This socially and culturally rooted homophobia took "the form of anti-gay legislation" (Berg, Ross, Weatherburn, \& Schmidt, 2013, p. 62 ) and went as far as neglecting the generally acknowledged and legally stated human rights and freedoms. Queers criticized and censured the idea of social hierarchy due to inborn sex qualities and advocated the statement of gender as a natural, inherent personal attribute different from sex and independent from socially and culturally construed norms and regulations. They proved Z. Bauman's assurance that "the word 'cultural' $<\ldots>$ is a misnomer dictated by the current standards of "political correctness"” and "humanmade [it] can in principle be human-unmade" (Bauman, 2010, p. 60).

The outspread of queer theory (frequently called 'coming out') is caused by the transformation and sometimes complete destruction of gender stereotypes, which, in their turn, are both formed and changed due to the mutation of social morals. In postmodern epoch, the traditional opposition "gender as difference" is substituted by "gender as diversity" (Annandale \& Clark, 1996). Hence, instead of the regular "gender as structure" there appears "gender as performance" (Annandale \& Hunt, 2000). The conclusion arises that as well as gender is construed in society, it influences the society the same way. It is a phenomenon of ambidextrous nature, a unity of fixed and flexible components, a dichotomy of stability and constant motion.

Accordingly, the present evolution of gender concept with its multiple meanings goes hand in hand with E. K. Sedgwick's theoretically grounded understanding of queer in its trespassing nature: "Queer is a continuing moment, movement, motive - recurrent, eddying, troub- 
lant. The word 'queer' itself means across - it comes from the Indo-European root twerkw, which also yields the German quer (transverse), Latin torquere (to twist), English athwart... queer ... is multiply transitive" (Sedgwick, 1994, p. xii). The whole philosophy of queer denies stability, routine, fixedness, and welcomes change, unexpectedness, diffusion, blur. It is a variable which opposes constancy and regularity and for this reason causes a miscellaneous social reaction, what, in its turn, attracts even greater attention and provokes a deeper interest.

With the course of time, queer abandoned its connotation of inferiority and entered scholarly research, culture and the arts bearing a new dimension of personality identification and novel approaches towards the analysis of formerly established norms and standards.

Scholarly discourse began to operate the term "queer" since the late 1980s - the early 1990s, especially after American scholar Teresa de Lauretis (1991) used it in her article "Queer Theory: Lesbians and Gay Sexualities: An Introduction", where the concept of queer was interpreted as a postmodernist articulation of alternative sex identity. As J. Tilsen and D. Nuland (2010) define its objectives, "queer theory rejects biological theories of sexual identity and calls into question so-called 'natural' sexuality" ( $p$. 66). Queer theorists announced that there were much more variations in sexual behaviour than in the reproductive one. Boundaries between heterosexuality and homosexuality are the social product, the result of social and cultural stereotypes formalization. Thus, queer, as any other identity, is a social construct. In societies with homonegative ideologies, "queer" reveals the semantics of challenge, counterculture towards the normative culture and heterosexual one, in particular. To be queer means to be different from the majority not only on the level of sexual practices but on the level of outlook, appearance, moral values. According to feminist theorists (J. Butler, B. Friedan, K. Millett), heteronormativity is a tool purposefully employed by the ruling authorities to preserve the existing power of heteronormative men upon women, homosexuals and the non-white: "The binary relation between culture and nature promotes a relationship of hierarchy in which culture freely "imposes" meaning on nature, and, hence, renders it into an "Other" to be appropriated to its own limitless uses, safeguarding the ideality of the signifier and the structure of signification on the model of domination" (Butler, 1990, p. 37). On the whole, "queer" is a semantically broad concept with blurred boundaries allowing the queer representatives treat their identity as floating, diffuse, fluid, shifting, thus being contrary to a stereotypically stable one. Queer identity is not a fixed norm but a constant process, performance, denial of dependence, public opinion and subjective appraisement.

Queer evinced the existence of two categories of sex: biological and social. The biological contents comprise a natural male/female body with its inborn features and functions as well as naturally predetermined relations. The social aspect of sex-identified bodies implies "all the practices and values that have come to represent those relationships" (Tilsen \& Nylund, 2010, p. 66). Thus, the biological binary does not always result in social binary. The diversity of sexual practices with the increased possibilities of selfpresentation in social and cultural ways, to say nothing about the progress in medical spheres in general and sex reassignment surgery in particular, enabled the outburst of identities with the non-normative socio-cultural representation of sex. This is generally known as gender within 
which traditional (heteronormative) and queer identities form a vast spectrum of personal identification.

Following the queer theory may lead to a conclusion of rejecting biology and essentialism as the aspects structuring natural ontological nature of a human being and his/her sexuality and gender. Both are stated as completely performative and constructionist. There is no erotic desire beyond a historical time and cultural stereotypes which make a body "normatively" attractive.

So, through the course of its semantic development and social apprehension, "queer" transferred from the marginal "outness" to an affordable option (Butler, 1993, p. 227) constituting a new dimension of gender identity formation and explication. "Decolonization of sex identity" is mainly achieved by forming the provocative "counter-discourse" (Sabiniarz, 2015) destined to review the hegemony of normative values, ruin gender dichotomy and the relating social conventions what will give rise to the formation of a new scope of identities, queer among them.

Semantics of "queer" is fixed in dictionaries: gay or lesbian, noting or relating to a sexual orientation or gender identity that falls outside the heterosexual mainstream or the gender bina$\mathrm{ry}^{1}$, an offensive way of describing a homosexual, especially a man, which is, however, also used by some homosexuals about themselves ${ }^{2}$, used as a disparaging term for a gay man or a lesbian; a lesbian, gay male, bisexual, or trans-

1 See Browse Dictionary (http://www.dictionary.com /browse); Cambridge Dictionary (http://dictionary. cabbridge.org.).

2 See Oxford Learner's Dictionary (http://www. oxfordlearnersdictionaries.com). gender person ${ }^{3}$. The meaning of deviant sex/gender behaviour is either missing ${ }^{4}$ or marked as slang or taboo 5 .

These definitions prove that so far there has not been any terminological certainty of the lexeme 'queer' what enables its interpretation and application. Socio-cultural background of the concept in question determines its lingual, mainly semantic, nature. By denying the natural feminine and masculine referent, the concept of queer undergoes resemantization: instead of the archaic pejorative semantics there arises multiplication of meanings which comprise the postmodernist assessment of sex and gender. Postmodernist queer-identity refutes social stereotypes and is constantly changing; it is 'elastic' and critically oriented (Fiol-Matta, 2002, p. XXIX). Postmodernist discourse (in its broad meaning) makes the terms "queer" and "other" synonymous.

Queer studies (Tilsen \& Nylund, 2010) alongside with queer politics resist institutionalized gender binary system ("dominant heteronormative matrix" (Escudero-Alias, 2009, p. 8) and suggests equal moral and social rights for heteronormativity and homonormativity as those reflecting the already existing practices but being outshadowed by so-called 'natural' sexuality with its hegemonic apprehension. Research in the nature of queer fits in the current popularization of diversity brought forth by the world official policies and mass media (remember the official slogan of Euro-2012 held in Poland-Ukraine

3 See The American Heritage Dictionary of the English Language (https://www.ahdictionary.com/word/ search.html).

4 See American Dictionary of the English Language. Retrieved February 2, 2019 from: http://websterdictionary1828.com.

5 See The American Heritage Dictionary of the English Language (https://www.ahdictionary.com/word/ search.html); Browse Dictionary (http://www. dictionary.com/browse); Cambridge Dictionary (http:// dictionary.cabbridge.org.); Oxford Learner's Dictionary (http://www.oxfordlearnersdictionaries.com). 
"Celebrate diversity"?). Queer enriches the dual identity division making it mosaic and fluctuating and introducing diversity into sex/gender combination; it "permeates everyday life and the myriad ways in which people take on identity positions whereby selves are transformed (or not)" (Woodward, 2007, p. 760).

One of the most conspicuous shifts is the transference of queer identity from the margins of social apprehension to the milieu of the community as a member with the equitable status. Homophobia is slowly being substituted by homonormativity advocated by "a more cautious, assimilationist approach" (Tilsen \& Nylund, 2010, p. 67). Positive resignification of the term itself and those identified as "queer" lead the way to include other identity categories, such as racial, national, religious, besides gender and sexuality, into open social practices and cultural appropriation.

As it becomes obvious, the term "queer", on the one hand, aims at generalizing all the gender identities grounded on alternative sex relations, on the other hand, it tends to overcome homophobic social attitudes and 'legitimize' sex minorities. This way a new philosophy of identity is being formed: "the separation of sexuality and gender produces other identity positions that question the very notions of "gay or lesbian"” (Escudero-Alias, 2009, p. 14).

Expansion of queer discourse in the late $20^{\text {th }}$ century coupled with postmodern ideology bringing about a new term in Anglo-American linguistics - "pomosexual" (postmodern + sexual) - (of or relating to a person who does not wish his or her sexuality to be put into a conventional category (see "The Free Dictionary"). The term was introduced by C. Queen and L. Schimel (1997), co-editors of the collection of essays "PoMoSexuals: Challenging Assumptions About
Gender and Sexuality" and was intended to describe "erotic reality beyond the boundaries of gender, separatism, and essentialist notions of sexual orientation" (cover inscription).

Lingual "verification" of queer as a personal identity takes place both in language and speech. Queer nominations do not form a separate glossary but enlarge the terminological system of gender studies. The functional style the queer vocabulary is used in determines its scope, semantics and stylistic colouring. Scholarly texts, mass media and fiction, are the spheres where the phenomenon of "queer" acquires distinctive linguistic features.

Like in philosophy and social sciences, the concept of "queer" has not got a homogeneous linguistic representation, either. The spectrum of lingual nominations of queer-identified individuals counts dozens. These come both from self-defined gender identities and socially apprehended phenomenon in question and nominated respectively, what may be considered as a right of any society as a speech community.

The queer phenomenon is variously reflected in contemporary texts. The incongruence between social and biological sex is designated by units of different language levels (morphological, lexical, syntactic) actualized in the texts of different styles. The nominations of those queeridentified vary across functional styles the lingual format of which primarily requires the selection of appropriate lexicon.

The first stylistic register to meet the social demand of queer marking is scholarly. The split of the gender binary and questioning of direct sex/gender correlation penetrated scholarly discussions in the middle of the $20^{\text {th }}$ century alongside with other hot-burning issues brought to light by the second wave of feminism and the socalled "sexual revolution". 
The term itself can hardly be found in a scholarly text as it tends to the normative use of terminology according to which a typical term is monosemantic and does not favour multiple interpretations. "Queer", on the contrary, is interpreted differently since the very phenomenon is not yet clearly designated. Scholars operate terms nominating every separate case of "gender dysphoria", as it is commonly attributed to any non-normative sex/sexuality correlation.

Avoidance of "queer" as a gender identity nomination results in descriptive passages or the use of lexical units with "sex" as a root morpheme:

The polyamorous pansexual, the monogamously married bisexual, and the ex-gay struggling with sexuality can all be read as having borderland sexualities within a shifting binary system (Callis, 2014, p. 70).

Here, an academic author uses a metaphoric phrase (borderland sexualities) to stand for a queer identity where interdependence between sex and sexuality loses its status quo.

Other authors consider queer as different from the already mentioned pansexuals and treat it as a phenomenon of the same nature as bisexuals and pansexuals but of a specific sexual needs (note the title of a scholarly paper "Bisexual, pansexual, queer: Non-binary identities and the sexual borderlands", published in Sexualities, Vol. 17 (1/2), 2014, pp. 63-80).

The publicist discourse "mirrors" queer as both resting on social stereotypes and formed by a journalist's personal view of the phenomenon. The contemporary nomination of the style journalistic - more adequately designates the social and lingual specificity of the texts it comprises. A present-day journalist is much more responsible for influence on public opinion than public speeches which are no longer a powerful instrument of persuasion but rather a PR necessity: "journalists compose their discourse from the discourses of their sources, taking decisions concerning how and why show or hide them" (Cunha, 2015). Hence, among the complexity of decisions, any journalist must take in every disputable situation, the concept of queer remains one of the most controversial. The confusion between the lexical meaning of "sex", "gender" and their correlation results in the public conflicts where the top politicians are involved:

The Trump administration has also aggressively shifted positions in cases involving gay rights, said Human Rights Campaign legal director Sarah Warbelow. In a New York case involving a skydiving instructor who alleged he was fired after telling a customer he was gay, the Trump administration's Justice Department weighed in to argue that a federal law barring "sex" discrimination means discrimination based on gender and doesn't cover sexual orientation. The Equal Employment Opportunity Commission under President Barack Obama took the opposite view (Gresko, 2017).

Here, the notions of "sex" discrimination and discrimination based on gender are treated semantically similar and do not imply sexual orientation what causes a legal collision as it violates personal rights (he was fired after telling $a$ customer he was gay). The nomination gay stands for a queer identity meaning social and cultural representation of sex, sexuality and a corresponding appearance and behavioural model known as gender.

The present-day newspaper text makes differences between queer identities and euphemistically calling them transgender people - the 
nomination often serving as an umbrella term for each of LGBT abbreviation (lesbian, gay, bisexual, transgender). Moreover, contemporary media texts do differentiate between them and apply appropriately regarding the mentioned above identities as peculiar, what can be seen, for example, in the title "Joining a public battle changed this private transgender woman's life" 6 where the contents reveal the life of a person with the male-to-female transition.

The fictional portrayal of such phenomenon "resuscitates" in the characters of postmodern literary texts. These types are recognized by a set of elements: appearance, clothes, behaviour, social positioning, speech. Queer identity is often recognized as the one practising same-sex sexual relationship and opposed to "traditional" heterosexual model, as in the following quote from a novel by K. Fu (2014): Perhaps from the way I sat there staring at the floor, he added quickly, "I am not queer. I've got a girl up in Innisfil"the character "he" justifies himself as not being queer by mentioning his relationship with a female (I've got a girl).

Literary text may be prescriptive regarding queer identification. Here a vast variety of queers is depicted and nominated, respectively. Among them - transgender (a person whose social and cultural behaviour does not correspond to the qualities traditionally attributed to biological sex). Transgenders do not undergo a set of medical and psychological manipulations aimed at changing the born sex. The lexeme itself is a blend of two roots - trans (clipped from transition) + gender (not sex) what means that it is vital to be perceived as a representative of the opposite sex, not to become the one. In fiction, such queer identity is designated either by a full form (transgender) or by clipped (trans), abbre-

6 See The Washington Post, April 30, 2016. viated $(T G)$ or converted (verbalized) form (transgendered). Transsexuals are predominantly known as those undergone SRS (Sex Reassignment Surgery) and the appropriate psychological and hormone therapy. Accordingly, fiction describes this transition in detail:

Then a male and female couple revealed to me that she was a male to female transsexual (MtoF) and he was a female to male transsexual (FtoM). Recently they had gone through the gender transition together (Evelyn, 1998, p. 18).

Fiction authors pave the way of introducing more exotic nominations into the social consciousness and speaking practice. The first text coming to mind is L. Feinberg's "Stone Butch Blues", American Library Association Gay \& Lesbian Book Award (now Stonewall Book Award) Winner of 1994, where the protagonists, gender non-conforming individuals, are designated by such lexemes as butch, stone butch, femme, drag-queen, drag-king, he-she, she-he etc. The diversification of queers proves their difference from the marginally reputed homosexuals, as the long existing simplified approach suggests.

The research of queer phenomenon functioning in the three types of discourse suggests the distinction in its philosophical, social and linguistic nature: a) in scholarly texts "queer" is treated as a concept whose essence may be subject to scientific analysis. Therefore, queer is nominated by vocabulary terminological units serving the signs of scientifically relevant objects or qualities; b) in mass media, "queer" is a verbalized stereotype, existent or newly formed. Publicist texts mark queer by widespread nominations from the stylistically neutral lexicon and suggests some novelties like the semantically resignified colloquial units or neologisms; c) lit- 
erary discourse brings to life queer characters positioned both as marginalized individuals and members of queer community members, where the scope of lingual units for their identification is the widest among the styles in question.

In conclusion, it is worth noting that in the epoch of postmodernism as an outlook vista and an instrument of perception and conceptualizing of knowledge when gender is posited as an option of personal choice rather than a born or constant attribute, the phenomenon of queer no longer remains in the outskirts of social consciousness but successively acquires its overt representation in the process of which lingual signs (lexemes, word combinations, stylistic devices etc.) are of vital importance.

\section{REFERENCES}

Annandale, E., \& Hunt, K., (2000). Gender Inequalities in Health: Research at the Crossroads. In E. Annandale, \& K. Hunt (Eds.), Gender Inequalities in Health (pp. 1-35). Philadelphia: Open University Press.

Annandale, E., \& Clark, J. (1996). What is Gender? Feminist Theory and the Sociology of Human Reproduction. Sociology of Health and Illness, 18(1), 17-44.

Bauman, Z., (2010). Identity: Conversations with Benedetto Vecchi. Cambridge: Polity Press.

Berg, R. C., Ross, M. W., Weatherburn, P, \& Schmidt, A. J. (2013). Structural and Environmental Factors are Associated with Internalised Homonegativity in Men who have Sex with Men: Findings from the European MSM Internet Survey (EMIS) in 38 Countries. Social
Science \& Medicine, 78, 61-69.

Butler, J., (1990). Gender Trouble: Feminism and the Subversion of Identity. New York: Routledge.

Butler, J., (1993). Bodies that Matter, on the Discursive Limits of Sex. New York \& London: Routledge.

Callis, A. S. (2014). Bisexual, Pansexual, Queer: Non-Binary Identities and the Sexual Borderlands. Sexualities, 17(1/2), 6380.

Cunha, G. X. (2015). The Multiplicity of Voices in the Journalistic Discourse: Study of Polyphony in Journalism in Light of a Modular Perspective of Discourse Organization. Intercom: Revista Brasileira de Ciências da Comunicação, 38(2). Retrieved February 2, 2019, from: http://dx.doi.org/10.1590/1809$\underline{5844201529}$.

Emslie, C., \& Hunt, K., (2008). The Weaker Sex? Exploring Lay Understandings of Gender Differences in Life Expectancy: A Qualitative Study. Social Science and Medicine, 67, 808-816.

Escudero-Alias, M., (2009). Long Live the King: a Genealogy of Performative Genders. Cambridge: Cambridge Scholars Publishing.

Evelyn, J., (1998). Mom, I Need to Be a Girl. Imperial Beach. Walter Trook Publishing.

Fiol-Matta, L., (2002). A Queer Mother for the Nation. Minneapolis, London: University of Minnesota Press.

Fu, K., (2014). For Today I am a Boy. New York: Houghton Mifflin Harcourt Publishing Company. Retrieved November 8, 2016, from: https://www. goodreads.com/reader/49839-for- 
today-i-am-a-boy?percent=1.385412.

Gresko, J., (2017). At high Court and Others, Trump Reverses Legal Course. The Times Record. Retrieved March 22, 2019, from: http://www.timesrecord. com/news/2017-09-29/Nation\%7C World/At high court and othersTrum p_reverses_legal_cour.html.

Lauretis, T., (1991). Queer Theory: Lesbians and Gay Sexualities: an Introduction. Differences: a Journal of Feminist Cultural Studies, 3(2), 71-97.

Oxford English Dictionary. Retrieved February 1, 2019, from: https://en.oxforddic tionaries.com/definition/queer.

Queen C. \& Schimel, L. (1997). PoMoSexuals: Challenging Assumptions about Gender and Sexuality. San Francisco: Cleis Press.

Sabiniarz, N., (2015). Intertextual Relations between Siegfried Sassoon's and Wilfred Owen's Poems and Pat Barker's Novel
"Regeneration". In A. Brabach-Kallas, $\&$ N. Strehlau (Eds.), Re-Imagining the First World War: New Perspectives in Anglophone Literature and Culture (pp. 140-151). Cambridge: Cambridge Scholars Publishing.

Sedgwick, E. K., (1994). Tendencies. London: Routledge.

The Free Dictionary. Retrieved February 13, 2019, from: http://www.thefreedic tionary.com.

Tilsen, J., \& Nylund D. (2010). Resisting normativity: Queer musings on politics, identity, and the performance of therapy. The International Journal of Narrative Therapy and Community Work, 3, 6470.

Woodward, K., (2007). On and Off the Pitch: Diversity Policies and Transforming Identities? Cultural Studies, 21(4-5), 758-778. 